\title{
Safety and Toxicology of Cannabinoids
}

\author{
Jane Sachs $^{1} \cdot$ Erin McGlade $^{1} \cdot$ Deborah Yurgelun-Todd $^{1}$
}

Published online: 13 August 2015

(C) The Author(s) 2015. This article is published with open access at Springerlink.com

\begin{abstract}
There is extensive research on the safety, toxicology, potency, and therapeutic potential of cannabis. However, uncertainty remains facilitating continued debate on medical and recreational cannabis policies at the state and federal levels. This review will include a brief description of cannabinoids and the endocannabinoid system; a summary of the acute and long-term effects of cannabis; and a discussion of the therapeutic potential of cannabis. The conclusions about safety and efficacy will then be compared with the current social and political climate to suggest future policy directions and general guidelines.
\end{abstract}

Keywords Cannabis $\cdot$ Cannabis safety $\cdot$ Cannabis policy $\cdot$ Cannabis efficacy $\cdot$ Cannabis

\section{Introduction}

There are more than 60 systematic reviews and meta-analyses discussing the safety, toxicology, potency, and therapeutic potential of exogenous cannabinoids. However, the general consensus of these reports is largely mixed and inconclusive. The uncertainty surrounding safety and efficacy of exogenous cannabinoids is not a product of the lack of research, but rather a product of the extreme variability in study methodology and

Electronic supplementary material The online version of this article (doi:10.1007/s13311-015-0380-8) contains supplementary material, which is available to authorized users.

Jane Sachs

jane.sachs@utah.edu

1 Department of Psychiatry, University of Utah, 383 Colorow Drive, Salt Lake City, UT 84108, USA quality. This review provides a summary of the current research on the safety and efficacy of exogenous cannabinoids, including a brief description of the chemical constituents of cannabis and how it interacts with the endocannabinoid system; a summary of what is known about the acute and long-term effects of cannabis; and a discussion of the therapeutic potential. Conclusions on safety and efficacy will then be compared with the current social and political climate in order to highlight the need for policy changes and general guidelines.

\section{Cannabinoids and the Endocannabinoid System}

Marijuana, or cannabis, colloquially referred to as weed, pot, grass, herb, bud, ganja, and so on, is the most commonly used illicit drug both nationally and internationally. Roughly, 180.6 million people worldwide report lifetime cannabis use [1], and 24.6 million people in the USA report past-month use [2]. Cannabis is derived from the plant Cannabis sativa, Cannabis indica, or Cannabis ruderalis, which is includes 70 known cannabinoids, including 7 cannabigerols, 5 cannabichromenes, 7 cannabidiols (CBD), 9- $\Delta$-9-tetrahydrocannabidiols (THC-9), 2- $\Delta$-8-tetrahydrocannabidiols (THC-8), 3 cannabicyclols, 5 cannabielsoins, 7 cannabinols, 2 cannabinodiols, and 9 cannabitriols [3]. In addition to whole-plant cannabinoids, there are a variety of synthetic cannabinoids (e.g., dronabinol and nabilone, both synthetic THCs) and cannabinoid extracts (e.g., the oro-mucosal spray nabiximols that contain both THC and CBD) that are used both clinically and in research [4].

THC and CBD are the most commonly researched cannabinoids in the literature and there is variability in the location, mechanism, and consequences of their actions. THC has a high affinity for cannabinoid type 1 receptors $\left(\mathrm{CB}_{1} \mathrm{R}\right)$ [5], which are found in the highest densities in the neuron terminals of the basal ganglia, cerebellum, hippocampus, 
neocortex, and hypothalamus and limbic cortex [6-10]. These brain regions are involved in motor activity, coordination, short-term memory, executive function, and appetite and sedation, respectively, and it is possible that THC activity in $\mathrm{CB}_{1} \mathrm{R}$ in these regions may explain many of the acute effects of cannabis use [9], which will be addressed later. The endocannabinoid system also contains cannabinoid type 2 receptors $\left(\mathrm{CB}_{2} \mathrm{R}\right)$, which are found primarily in immune cells and tissues $[6,11]$. There is evidence that activity of endogenous cannabinoids (e.g., anadamide) and exogenous cannabinoids (e.g., THC) at $\mathrm{CB}_{2} \mathrm{R}$ may have opposing effects on the immune system, with endogenous cannabinoids enhancing immune response and exogenous cannabinoids having immunosuppressant effects [12]. In contrast to THC, CBD has relatively low affinity for both $\mathrm{CB}_{1} \mathrm{R}$ and $\mathrm{CB}_{2} \mathrm{R}$ [5]. Despite the relatively low affinity of $C B D$ at $\mathrm{CB}_{1} \mathrm{R}$ and $\mathrm{CB}_{2} \mathrm{R}$, it demonstrates high potency as an antagonist. Furthermore, there is evidence that $\mathrm{CBD}$ may mitigate some of the effects of THC [13-15], potentially through indirect agonism, either by augmenting $\mathrm{CB}_{1} \mathrm{R}$ constitutional activity or endocannabinoid tone [5].

The already complex interactions of exogenous and endogenous cannabinoids in the cannabinergic system are further obfuscated by different methods of administration, inconsistent dosing measures, and highly variable cannabinoid content of cannabis plants. Cannabinoid content and consequent potency has shown extreme variance depending on the light, temperature, humidity, and soil type during cultivation, as well as genetic factors [16-19]. This is evidenced by changes in potency over time as more cannabis is grown in doors and as strains are engineered with different THC and CBD ratios [17, 19, 20]. Furthermore, the method of administration (e.g., oral, smoked, vaporized) and form of cannabinoid consumed (e.g., stems and buds, hashish, hash oil, extract, synthetic) can impact the bioavailability and consequently the response to use $[4,6,18$, 21-25]. This is particularly salient when comparing recreational and medical forms of cannabis. Collectively, these factors contribute to the difficulty in deciphering the relative safety and efficacy of cannabinoids both medically and recreationally.

\section{Safety: Acute and Long-term Effects}

Despite the variability in research methodology and quality, there are some generalizable findings regarding the acute and long-term effects of exogenous cannabinoids.

\section{Effects on Physical Health}

\section{Cardiovascular}

Cannabinoids have shown both acute and long-term cardiovascular effects. Acute dose-dependent effects of cannabis include tachycardia, increased cardiac labor, systemic vasodilation, and increased blood pressure [15, 26-29]. More severe effects such as increased angina, myocardial infarction, cardiac death, and cardiomyopathy have been recorded in individuals with pre-existing cardiovascular conditions $[16,20,28$, 30], and as such it is recommended that these individuals avoid cannabis use [31]. Paradoxically, the long-term cardiac effects of chronic cannabis use include bradycardia and hypotension, which may reflect tolerance and down-regulation over time $[16,32,33]$.

\section{Respiratory}

Smoking is one of the main methods of cannabis administration. As such, the impact that smoking cannabis has on the respiratory system has been a point of serious concern for policy makers. A number of acute and chronic effects on the respiratory system are associated with cannabis use. Specifically, acute cannabis use has been shown to increase inflammation of large airways, increase airway resistance, and destroy lung tissue $[15,20,29]$. Further, there is evidence that chronic cannabis use also results in increased risk of chronic bronchitis [20, 29, 34], increased risk of emphysema [29], chronic respiratory inflammation $[20,26,29,35]$, and impaired respiratory function [27, 28].

\section{Cancer}

Although there is a pathophysiological process by which chronic cannabis use could confer an increased risk of cancer the epidemiological literature on the causal relationship is mixed [34-36]. Hashibe et al. [36] found that smoking cannabis was not associated with an increased risk of smokingrelated cancers (e.g., lung, head, and neck), but might be associated with an increased risk of prostate cancer, cervical cancer, and glioma. Conversely, Reece [29] reported that smoking cannabis is associated with an increased risk of lung cancer. Other findings suggest that while cannabis does increase the risk of lung cancer, it is still lower than the risk of lung cancer associated with tobacco [20].

Comparisons of cannabis and tobacco smoke have produced mixed findings. Repp and Raich [20] found that cannabis smoke contains ammonia, hydrogen cyanide, nitric oxide, and aromatic amines at 3-5 times the rate of tobacco smoke. However, Maertens et al. [37] found that aside from the cannabinoids and nicotine, cannabis and tobacco smoke condensates contained mixtures that were qualitatively similar. They also found that cannabis smoke condensate and tobacco smoke condensate influence the same molecular processes but have subtle pathway differences that potentially account for differential toxicities and the mixed results with respect to lung cancer [37]. 


\section{Immune System}

Given the prevalence of $\mathrm{CB}_{2} \mathrm{R}$ in immune cells and tissues, exogenous cannabinoids likely produce immunological impacts both acutely and chronically [11]. However, the influence of exogenous cannabinoids on the immune system is multifaceted and while comprehension is improving, continued research is required [16]. While there is some evidence of immunosuppressive properties of cannabis [15, 26], there is evidence of anti-inflammatory and neuroprotective effects of CBD [13]. Specifically, CBD inhibits interleukin-10, while also increasing interleukin-8, which could have potentially therapeutic results in immune disorders [13]. The presence of both positive and negative impacts of cannabis on the immune system illustrate the potential biphasic impact on the immune system, with benefits at high and low levels and detriments at moderate levels $[13,15,26]$. Similarly, SuarezPinilla et al. [12] found that endocannabinoids enhanced immune response, while exogenous cannabinoids had immunosuppressant effects.

\section{Sleep}

There is mixed evidence regarding the impact of cannabinoids on sleep [38]. Sedation and somnolence are commonly described acute adverse effects of heavy cannabis use [4, 39-41]. Furthermore, cannabis has been shown to increase total sleep time in individuals with difficulty sleeping, including in cancer patients with chronic pain [42], individuals with post-traumatic stress disorder [43], and individuals with insomnia [41]. However, cannabis has been show to decrease slow wave sleep $[6,38]$. This suggests that a consequence of the increased sleep time may be decreased sleep quality. There is also some evidence that sleep difficulty is a withdrawal symptom associated with cannabis use disorders [15, 44].

\section{Effects on Cognition}

It is clear that exogenous cannabinoids have an effect on cognition; however, there is considerable variability between the acute neuropsychological, chronic neuropsychological, and neuroimaging findings.

\section{Acute Effects}

Cannabis use has well evidenced acute impacts on cognition [13, 16, 20, 26, 34, 45-48]. Specifically, it has been reported to impair free recall [16, 20, 45], acquisition [16], working memory [15, 45], and procedural memory [20, 45]. Impairments are also demonstrated on measures of attention [15, 20, 48], impulsivity [15, 20], inhibition [49], sensory perception [26], and executive function [20, 26, 50-52]. On other measures of cognitive function the, evidence of deficits is less clear. Some studies report impairments in gross and simple motor tasks after acute cannabis use $[13,15,16,26$, 34], whereas others find that evidence on impairments in psychomotor function is inconclusive [45]. Likewise, evidence for the impact of acute cannabis use on abstract reasoning and decision making is mixed, with some reports of impairment $[20,34]$, and other studies demonstrating no impact [15, 45]. Although there are clear acute cognitive effects of cannabis use, the majority are relatively short lived and diminish over time with abstinence [20, 26, 48, 53, 54].

\section{Chronic Effects}

Most studies have found limited evidence of persistent neuropsychological deficits among cannabis users [20, 45, 47, 51, 53-55], particularly for those who initiated cannabis use as adults [56]. However, the risk of long-term cognitive effects of cannabis use appears to increase with earlier age of onset [26, $45,47,48,56-58]$, frequency of use [15, 34, 45, 47, 49, 59], and duration of use [15, 34, 45, 47, 49]. For instance, Repp and Raich [20] found that adolescents who initiate cannabis use before the age of 15 years demonstrate persistent pronounced deficits in visual attention, verbal fluency, inhibition, short-term recall, impulsivity, and executive functioning. Similarly, Meier et al. [46] found that cessation of cannabis did not fully restore cognitive deficits among adolescent-onset cannabis users, and may result in a greater loss of IQ in adolescence [46, 57]. Moreover, adolescent-onset users diagnosed with cannabis dependence prior to the age of 18 years were more likely to become persistent users and showed impairments in executive functioning and processing speed [46]. Other factors that may influence long-term neuropsychological effects and make between-study comparisons difficult include length of abstinence and the THC to CBD ratio [26, 45, 47]. This is particularly interesting because studies of acute administration suggest that $\mathrm{CBD}$ may be protective against the negative cognitive impacts of THC [45].

\section{Neuroimaging Studies}

In addition to the neuropsychological assessments, a number of studies have applied neuroimaging techniques to examine the effects of exogenous cannabinoids on brain structure, function, and connectivity. Recent morphological studies of adults and adolescents have found structural abnormalities in $\mathrm{CB}_{1} \mathrm{R}$-rich areas, particularly in the medial temporal and frontal cortices and cerebellum, and most notably among chronic cannabis users [6, 28, 49, 60-64]. Specifically, structural neuroimaging findings suggest there are reductions in parahippocampal, hippocampal, and thalamic volume associated with chronic cannabis use when compared with healthy controls [47]. Studies of chronic adolescent cannabis users also showed structural differences in the hippocampus and 
amygdala [65]; gray matter volume reduction in the medial temporal cortex, temporal pole, parahippocampal gyrus, insula, and orbitofrontal cortex [6]; and reduced prefrontal volumes and white matter integrity when compared with controls [49, 60]. Studies of marijuana users who have also used alcohol or tobacco have also shown changes in brain morphometry. Heavy marijuana using adolescents with cooccurring alcohol use were found to have increased cortical thickness, particularly in frontal and parietal regions [66]. An investigation by Wetherill et al. [67] comparing adult cannabis users with and without co-occurring tobacco use reported that both groups showed smaller thalamic gray matter volume than nonusers; however, both cannabis groups and a cohort of tobacco smokers showed increased left putamen volumes. Reduced left cerebellum gray matter in nicotine users but not in cannabis users suggested that nicotine and cannabinoids exert differential effects on regional brain tissue volume [67]. Moreover, evidence suggests that in adolescents functional alterations may appear shortly after starting drug use [60]. Therefore, while cannabis use may result in morphological alteration in adults and adolescents, early onset, longer duration, and heavier use are associated with more significant alterations in structural integrity [49].

Alterations in brain function have also been observed during cannabis use. There is strong evidence that acute cannabis administration increases cerebellar and prefrontal blood flow $[49,62,65]$. However, resting state prefrontal blood flow is lower in chronic cannabis users when compared with controls $[49,60,62]$. This may represent the down-regulation of $\mathrm{CB}_{1} \mathrm{R}$ receptors during the resting state among chronic users [60]. Additionally, acute administration of cannabis may increase anterior cingulate cortex activity during cognitive tasks and increase brain metabolism in multiple regions during impulsivity tasks $[49,62,68,69]$. The greater task-related activation among chronic cannabis users may reflect impaired efficiency and recruitment of additional regions [49, 60, 62, 70].

Furthermore, there is also evidence that adults who initiated regular cannabis use in adolescence may have impaired functional connectivity [34]. Specifically, neuroimaging data indicate reduced connectivity within prefrontal networks, which may be partially responsible for deficits in executive function among regular heavy cannabis uses who initiated use in adolescence [34]. These abnormalities may be explained by the influence of cannabis on the still-developing endocannabinoid system, particularly the disruption of normal pruning during adolescence when extensive re-organization of gray and white matter is occurring $[57,60]$. However, while changes in white matter have been reported in adolescent cannabis users, the mechanisms for the change and long-term effects have not been fully characterized [65].

Finally, magnetic resonance spectroscopy (MRS) is a noninvasive measurement technique that enables the in vivo quantification of a range of neurometabolites, including $\gamma$ - aminobutyric acid (GABA) and glutamate. The effects of chronic marijuana exposure have been examined through the application of MRS imaging. For example Chang et al. [71] reported reduced glutamate, choline, and myoinositol concentrations in the basal ganglia of chronic marijuana users. Applying MRS imaging, Hermann et al. [72] identified lower concentrations of $\mathrm{N}$-acetyl aspartate in the dorsolateral prefrontal cortex of adult smokers. Prescot et al. applied recently completed a small pilot study using proton MRS to the anterior cingulate of marijuana smoking and non-smoking adolescents and also found reduced $N$-acetyl aspartate, as well as reduced glutamate and creatine in marijuana-using individuals [73].

\section{Effects on Mental Health}

Disruptions of the cannabinergic system may have important implications for a number of neurobehavioral processes [74]. There is evidence of an association between cannabis use and both acute and chronic mental illness and psychiatric conditions, including depression, anxiety, psychosis, bipolar disorder, schizophrenia, and an amotivational state [29, 34]. However, given the variation in the disease process, as well as inconsistent cannabis dosing and composition, the full nature of the associations remains to be clarified.

In studies of cannabis use and bipolar disorder, it appears that cannabis use may exacerbate or trigger manic symptoms among individuals previously diagnosed with bipolar disorder. Gibbs et al. [75] found a 3-fold increase in risk for onset of manic symptoms after cannabis use [75]. However, there does not seem to be evidence that cannabis use is a risk factor for developing bipolar disorder [75]. Mixed findings are found when examining the relationship between cannabis use and depression and anxiety. There is some evidence that cannabis use and cannabis withdrawal may result in acute depressed mood $[15,29,76]$. Similarly, studies suggest that cannabis may increase acute anxiety $[4,15,77]$. The picture of chronic anxiety and depression and cannabis use is more complicated, in part because frequent cannabis users have both a higher prevalence of anxiety disorders, and individuals with anxiety have high rates of cannabis use [77, 78]. The fact that individuals who initiate cannabis use in adolescence may develop depression and anxiety that persists after cessation may also influence this relationship [20]. Furthermore, interpreting causality is complicated by the fact that a low concentration of THC may have anxiolytic effects, whereas higher concentrations produce anxiogenic effects [15, 77], and the evidence that CBD may mitigate the effects of THC in animal models of anxiety [5].

A significant portion of the literature dedicated to cannabis use and mental health focuses on the relationship between cannabis use and schizophrenia and psychosis. A number of studies suggest that acute cannabis exposure may induce 
temporary psychosis $[4,26]$. Additionally, chronic cannabis use may trigger psychosis and schizophrenia in individuals with a predisposition or genetic susceptibility to mental illness $[12,20,26,57,65,79,80]$. This appears to occur in a dosedependent manner, such that heavy cannabis use, longer duration, greater potency, and early onset of use may be more closely aligned with disease trajectory, often significantly advancing the first psychotic episode and development of schizophrenia [15, 20, 57, 65, 80, 81]. Additionally, lifetime cannabis use has been associated with higher schizotypy scores [82], and cannabis may exacerbate pre-existing symptoms of psychosis and schizophrenia [6]. Furthermore, individuals with psychosis may be more vulnerable to brain volume loss, which has been suggested as a result of cannabis exposure $[6,63,83]$.

Although there is strong evidence that early cannabis use among at-risk individuals may increase the likelihood of developing schizophrenia or psychosis at a later time point, additional research is necessary to parse out the intricacies of the interaction between THC and CBD on the cannabinergic system. For example, several systematic reviews found that while cannabis use may increase subclinical symptoms of psychosis, the findings to date do not support an association between cannabis use and first psychosis [84]. Additionally, there is some evidence that cannabis with a high CBD and low THC content may mitigate psychosis $[5,85,86]$.

\section{Public Health and Safety}

In addition to the physical, psychological, and cognitive effects of cannabis, there are clear concerns about public health and safety. A potentially serious public health effect of cannabis use is a high incidence of drugged driving and motor vehicle accidents $[16,26]$. Moreover, driving impairment occurs in a dose-dependent fashion [26, 87], and individuals driving under the influence of cannabis are anywhere from 2 to 7 times more likely to be involved in both fatal and nonfatal motor vehicle collisions [20, 34].

Another risk associated with cannabis use is addiction and cannabis dependence. Nine to ten percent of individuals who initiate cannabis use will become addicted $[6,20,34]$. That number increases to $16-17 \%$ among individuals who initiate use as an adolescent and 25-50\% among individuals who use cannabis daily [20]. The risk for addiction appears to wane as the individual ages, such that it is rarely addictive if use begins after the age of 25 years [65]. However, currently $6.5 \%$ of twelfth graders in the USA report daily cannabis use [34], and there is evidence to suggest that as perception of harm decreases, prevalence of use increases [88]. This is particularly important because early exposure to cannabinoids may alter the reactivity of the dopamine reward centers in the brain, thereby increasing vulnerability to abuse of and addiction to other substances, and adding support to the gateway hypothesis $[34,89]$. Furthermore, heavy cannabis use may be linked to negative consequences downstream, including lower income, greater need for socioeconomic assistance, unemployment, and lower life satisfaction [34].

There is also evidence of negative impacts on maternal and child health. Cannabis use during pregnancy is associated with poor physical outcomes, including birth defects, low birth weight, and an increased risk of childhood cancer, as well as poor neurodevelopmental outcomes, including aggressive behavior and attention problems in girls $[20,29,35]$. For example, children who were exposed to marijuana prenatally are more likely to demonstrate decreased problem-solving skills, as well as poor memory and attention [90, 91]. Similarly, babies exposed to marijuana prenatally show traits indicative of neurological development problems [92, 93].

\section{Therapeutic Potential}

Despite the acute and chronic side effects of cannabis use, there is a growing body of evidence suggesting the therapeutic potential of cannabis. This is likely facilitated, in part, by the fact that certain cannabinoids, like CBD, have been wellstudied and are well tolerated and safe in humans, even at high doses and chronically [94]. Exogenous cannabinoids, including nabiximols, CBD extract, and even smoked cannabis, have been recommended medically for cancer, anorexia, AIDS, chronic pain, spasticity, glaucoma, arthritis, migraine, and other illnesses for which cannabis provides relief $[15,34]$. Additionally, the American Academy of Neurology published a position statement concluding that medical cannabis is 'probably effective' for some symptoms of multiple sclerosis (MS), including spasticity, central pain, spasms, and urinary dysfunction; is 'probably ineffective' for levodopa-induced dyskinesia of Parkinson's disease (PD); and of 'unknown efficacy' in nonchorea symptoms of Huntington's disease (HD), Tourette's syndrome, cervical dystonia, and epilepsy $[6,95]$.

\section{Neurological Conditions}

The literature on the therapeutic potential of exogenous cannabinoids in the treatment of MS has been the most promising. There is evidence that cannabinoids may have neuroprotective and anti-inflammatory effects in individuals with MS through the regulation of cytokine levels [96]. However, it should be noted that the degree of therapeutic potential varies according to preparation. There is evidence that oral cannabis extract and nabiximols, an oral mucosal spray containing a 1:1 ratio of CBD:THC, reduce spasticity in patients with MS $[4,6,20$, 95]; however, smoked marijuana is of uncertain efficacy [95]. Similarly, the American Medical Association found that a review of small, short-term randomized controlled trials demonstrated that smoked cannabis reduces neuropathic pain, 
improves appetite, and may relieve spasticity and pain in patients with MS [97]. There is also some evidence of reduced muscle stiffness, relief from pain, and improved sleep quality among patients with MS using oral cannabis extract [6]; however, these findings arise from subjective assessment of symptom relief and may be secondary to improvements in spasticity $[6,96]$. While many studies suggest that cannabis may be a useful therapy for MS-related symptoms, it is important to note that not all studies assess adverse physical and cognitive impacts. Wade et al. [98] found that patients with MS who demonstrate symptom relief after use of nabiximols can continue use in the long term without tolerance, intoxication, serious adverse effects, or decrease in subjective symptomatic relief. Although the literature suggests only mild adverse physical effects associated with medical cannabis use for treatment of MS, recent studies of cannabis use in patients with MS have reported cognitive diminishment and impairment of cerebral compensatory mechanisms when compared directly with patients with MS who have not used cannabis [99-101]. Investigators from these studies raised concerns regarding the use of cannabis in a patient group with cognitive challenges prior to cannabis use.

Evidence for efficacy in other neurological conditions relies heavily on testimonials and anecdotes [20]. Animal models demonstrate the antiepileptic potential of cannabis $[6,102]$, and suggest that CBD may enhance the efficacy in preclinical models of epilepsy [5]. Nevertheless, there have been few controlled trials. One systematic review found that short-term daily cannabis use is safe in individuals with epilepsy, but there is currently insufficient evidence to form a conclusion about efficacy [34, 102]. Similarly, preclinical models Alzheimer's disease, $\mathrm{PD}$, and $\mathrm{HD}$ are mechanistically promising $[6,95,103]$. $\mathrm{CB}_{2} \mathrm{R}$ expression correlates with levels of $\beta$-amyloid- 42 and plaque density [104]. Furthermore, cannabinoids may inhibit tau hyperphosphorylation and prevent $\beta$-amyloid aggregation $[105,106]$, suggesting therapeutic potential in models of Alzheimer's disease. Similarly, the presence of striatal cannabinoid receptors on GABA terminals demonstrates a mechanism in which cannabinoids could improve dyskinesia by improving GABA transmission in the globus pallidus in patients with PD [107]. Finally, animal models of HD using cannabinoids as treatment demonstrate preservation of striatal neurons [108]. However, despite the success of these preclinical animal models, evidence from human studies remains scant [6].

\section{Psychiatric and Psychological Conditions}

Research on the therapeutic benefits of exogenous cannabinoids on psychological conditions is equally sparse. Early clinical trials have demonstrated that high-dose oral CBD may have an anxiolytic effect, possibly through $5-\mathrm{HT}_{1 \mathrm{~A}}$ agonism $[5,41]$. In patients with schizophrenia elevated anadamide levels are negatively correlated with psychotic symptomology, which suggests a protective role [86]. In spite of this, the benefits of CBD monotherapy are not consistently demonstrated in individuals with bipolar disorder or schizophrenia $[41,109,110]$. There is some evidence that cannabis may have a beneficial impact on sleep quality among individuals with post-traumatic stress disorder $[6,43]$. However, more research is needed to confirm and further explore the therapeutic effects of cannabis or synthetic cannabinoids on psychological conditions.

\section{Other Medical Conditions}

Some of the first conditions medicinal cannabis was approved for include glaucoma, chronic pain, and nausea and vomiting associated with cancer treatments and AIDS. There is good evidence that exogenous cannabinoids can decrease intraocular pressure in individuals with glaucoma $[20,21]$. However, in order to have a clinically significant impact the dose and frequency of use needs to be extremely high, which may increase the likelihood of negative side effects [34]. Medicinal cannabis has also been used to treat chronic neuropathic pain, particularly when conventional methods do not work. Current research suggests that cannabinoids, including oral cannabis, THC, and nabiximols, provide effective analgesia $[4,6,34$, 111-113]. There is also some evidence that cannabinoids may be safe and moderately effective in the treatment of pain associated with fibromyalgia and rheumatoid arthritis [34, 42, 114]. Treatment with medicinal cannabis has resulted in decreased need for antiemetic in individuals undergoing chemotherapy $[34,39,113,115,116]$. Additionally, while medicinal cannabinoids (e.g., nabilone, dronabinol, and levonantradol) are not significantly better at treating nausea or vomiting than conventional medications, patients receiving chemotherapy often prefer them [34, 39, 116, 117].

Although there is evidence for the therapeutic potential of exogenous cannabinoids in the treatment of a number of conditions there is still serious trepidation regarding the potential negative side effects. A large systematic review of the adverse events associated with the use of medical cannabis demonstrated that short-term use of existing medical cannabinoids increases the risk of nonserious adverse events including mildto-moderate sedation, dizziness, dry mouth, nausea, and poor attention [117]. The rates of serious adverse events (e.g., relapse of MS, vomiting, and urinary tract infections) were not different from controls [117]. Further research is needed to better understand the long-term effects of medical cannabis.

\section{Policy Perspective}

\section{Policy Timeline and Research Limitations}

Perceptions and policy regarding cannabis have vacillated widely over the years, reflecting the relative temporal valence 
of scientific evidence compared with public opinion at a given point in time. For example, California legalized medical cannabis in 1996, despite the federal ban [118]. Shortly thereafter, the Institute of Medicine issued a report acknowledging the potential therapeutic benefits of cannabis, but calling for more research. More recently, the pace and quality of research has been limited by stagnant policy. Cannabis was and still is categorized as a Schedule I drug, which means it is identified as potentially addictive without any medical benefit. As a Schedule I drug, the process for conducting research is extremely complicated. Researchers must have a Drug Enforcement Agency Schedule I license, approval from their institution, and funding. Obtaining all 3 is extremely challenging and has been a limiting factor in the advancement of current cannabis research. In lieu of the ability to conduct randomized controlled trials, many researchers must instead focus their efforts on retrospective cohort studies, case reports, and observational studies. There has been significant debate over the merits of re-classifying cannabis as a Schedule II drug, as it would greatly increase research accessibility and consequently methodological quality [119]. Ironically, the limited clinical research coupled with divisive public opinion and perception hinders the reclassification. In addition to reclassification, research regarding cannabis safety and efficacy is affected by a lack of standardization. Current clinical research findings are constrained by inconsistency in definitions of what constitutes a standard dose and how to quantify and standardize methods of administration [120]. Additionally, a great deal of the research relies on subjective, patient report, and patient-driven symptoms rating scales [95]. Ultimately, the federal policies remain stagnant because the process is circular; the clinical research methods and standardization are limited by the current policy, but the current policy is difficult to change because the lack of research standardization produces mixed findings.

\section{Public Perspective and Perceived Risk}

Despite the stagnant federal policy, public perspective and perceived risk has demonstrated a noticeable shift. According to the 2012 National Survey on Drug Use and Health, cannabis is the most commonly used illicit drug in the USA with a national prevalence of cannabis use in the past month at $7 \%$ [121]. Similarly, the Monitoring the Future Study has documented increased rates of use and decreased perceived risk between 2002 and 2012 among high-school students $[88,122]$. This is further evidenced by the fact that $62 \%$ of recent cannabis initiates were 18 years of age or younger when they first used [121]. The epidemiological evidence on use and perceived risk demonstrates a relatively clear trend in public opinion that is reflected in state but not federal policy. Despite a federal ban and limitations in the quality of evidence surrounding the potential risks associated with cannabis use, medical cannabis is currently legal in 23 states and the District of Columbia, and recreational cannabis is legal in 4 states $[6,123]$.

\section{Implementation Variation}

Currently, there is state-by-state variation in the way medical cannabis legislation is designed and implemented. Specifically, there is inconsistency in the way in which states regulate patient use and access, caregiver rights, the role of dispensaries, and product safety and packaging requirements [124]. First and foremost, states can choose to enact medical cannabis legislation by 1 of 2 mechanisms, either through the introduction of statutory provisions or through the creation of an amendment to the state's constitution. The majority of states with medical cannabis laws have opted to enact statutory provisions, in part because the process is easier, though also less stable. The next aspect of legislative design is determining who qualifies for medical use and how they obtain permission. Because physicians are subject to sanctions from the federal government, they cannot prescribe cannabis but rather must recommend use. The contexts for which a recommendation can be given vary. Some states require diagnosis of a medical condition in addition to a physician recommendation, whereas others simply require a physician recommendation [124]. After obtaining a physician recommendation there are 2 approaches an individual can follow to procure medical cannabis: home cultivation or from an approved dispensary. Currently, 15 out of 24 jurisdictions allow home cultivation; however, the circumstances under which home cultivation is permissible and the defined quantity allowed in circulation varies by jurisdiction (Table 1) [123]. Similarly, 19 out of 24 states allow dispensaries or compassionate care centers to engage in some combination of dispensing activities, including acquisition, possession, cultivation, manufacturing, delivery, transfer, selling, supplying, and dispensing of cannabis [123, 124]. Finally, there is variation in legal protections afforded to physicians, caregivers, and patients who may be involved in recommending, acquiring, or using medical cannabis. There are 2 types of protections: legal privilege that prevents the state from bringing criminal chargers, and affirmative defense that allows the individual to prevail against the criminal charges. Currently, legal protections for patients and caregivers differ from those for recommending physicians. Namely, the protections prevent the state from bringing charges against the physicians, whereas patients and caregivers may be tried but have affirmative defense that excuses criminal culpability [124].

While policy should be supported by the scientific evidence, the ability to generate quality evidence thus far has been hindered by federal policy. This has resulted in a piecemeal state-based system without the ability to fully assess or implement safeguards [97]. As legalization of medical and 
Table 1 Medical and recreational marijuana legislation by jurisdiction [123]

\begin{tabular}{|c|c|c|c|c|c|c|}
\hline Jurisdiction & $\begin{array}{l}\text { State authorizes } \\
\text { medical marijuana }\end{array}$ & $\begin{array}{l}\text { States authorizes } \\
\text { recreational marijuana }\end{array}$ & $\begin{array}{l}\text { Affirmative } \\
\text { defenses }\end{array}$ & $\begin{array}{l}\text { Home } \\
\text { cultivation }\end{array}$ & $\begin{array}{l}\text { State regulates } \\
\text { dispensaries }\end{array}$ & $\begin{array}{l}\text { Product safety } \\
\text { testing }\end{array}$ \\
\hline Alaska & Yes & Yes & Yes & Yes & No & No \\
\hline Arizona & Yes & No & No & Yes & Yes & Yes \\
\hline California & Yes & No & Yes & Yes & Yes & No \\
\hline Colorado & Yes & Yes & Yes & Yes & Yes & Yes \\
\hline Connecticut & Yes & No & Yes & No & Yes & Yes \\
\hline District of Columbia & Yes & Yes & Yes & No & Yes & Yes \\
\hline Delaware & Yes & No & Yes & No & Yes & Yes \\
\hline Hawaii & Yes & No & Yes & Yes & No & No \\
\hline Illinois & Yes & No & No & No & Yes & Yes \\
\hline Massachusetts & Yes & No & Yes & Yes & Yes & Yes \\
\hline Maryland & Yes & No & No & No & Yes & No \\
\hline Maine & Yes & No & Yes & Yes & No & Yes \\
\hline Michigan & Yes & No & Yes & Yes & Yes & No \\
\hline Minnesota & Yes & No & No & No & No & Yes \\
\hline Montana & Yes & No & Yes & Yes & Yes & No \\
\hline New Hampshire & Yes & No & Yes & No & Yes & No \\
\hline New Jersey & Yes & No & No & No & Yes & Yes \\
\hline New Mexico & Yes & No & Yes & Yes & Yes & Yes \\
\hline Nevada & Yes & No & Yes & Yes & Yes & Yes \\
\hline New York & Yes & No & No & No & Yes & Yes \\
\hline Oregon & Yes & No & Yes & Yes & Yes & Yes \\
\hline Rhode Island & Yes & No & Yes & Yes & Yes & No \\
\hline Vermont & Yes & No & No & Yes & Yes & Yes \\
\hline Washington & Yes & Yes & Yes & Yes & No & No \\
\hline
\end{tabular}

recreational cannabis at the state level becomes more prevalent, jurisdictions are making an effort to implement safeguards, including safety testing, packaging requirements, labeling requirements, media advertisement restrictions, and distribution site features. However, of the 24 jurisdictions that have legal medical or recreational cannabis law, only 15 have product testing and regulation requirements, and only 8 have mandatory testing [123]. Therefore, while public perspective trends suggest continued state-based legislative change, the lack of federal regulation and infrastructure poses serious safety concerns.

\section{Discussion: Future Directions}

The literature on medical and recreational cannabis suggests clear discordance between current federal and state policies, public opinion, and the scientific evidence. Moreover, this discordance appears to hinder the implementation of both high quality research and adequate safeguards.

The scientific evidence is often inconclusive and burdened by methodological inconsistency. The classification of cannabis as a Schedule I drug limits the type and quality of research, forcing assessments of safety and efficacy to rely on observational studies. Furthermore, definitions of standard dose vary, as do means of administration, cannabinoid content, potency, and reason for use (recreational and medical). Despite the methodological challenges, the findings to date illustrate relatively clear acute cardiovascular, respiratory, cognitive, psychological, and public health effects associated with both recreational and medical cannabis use. However, the documented persistence of these acute effects is considerably more variable. Long-term cardiovascular and respiratory consequences of cannabis use are fairly well evidenced. However, the findings regarding long-term cognitive, psychological, and immune effects are less clear. Few studies have assessed the long-term impact of cannabis on the immune system, and questions remain regarding the relative impacts of $\mathrm{THC}$ and CBD on immunity. Likewise, among healthy adults there is mixed evidence for long-term cognitive and psychological impacts of heavy cannabis use after discontinuation and washout $[4,20,45-47,55]$. Some studies do report long-term deficits in learning and memory, but the findings are inconsistent $[4,15,34,45,47,55]$. It appears that persistent cognitive diminishment and psychological impacts are closely related to early age of onset, increased duration, and frequency of 
use. Age of onset and frequency of use also have an impact substance abuse and dependency later on, with addiction rates of $16-17 \%$ among individuals who initiate use as an adolescent and $25-50 \%$ among individuals who use cannabis daily [20]. Collectively, these findings begin to depict vulnerable populations who may be negatively affected by the effects of by cannabis use, including adolescents, individuals with current or past substance use disorders, individuals with a personal or family history of mental illness, those that have compromised cardiovascular, respiratory, or immune systems, and those who are pregnant [31]. However, among the average adult user the health risks associated with cannabis use are likely no more dangerous than many other indulgences, including alcohol, nicotine, acetaminophen, fried foods, and downhill skiing [125-128]. This viewpoint is echoed in regard to medical cannabis as therapy. The side effects of conventional medications are weighted against the potential benefits, but this same logic is rarely applied to discussions of medical cannabis. This dilemma is further exacerbated by the fact that research on the therapeutic potential of cannabis relies on testimony and anecdote and is consequently heavily subjective.

Given these findings one option for the future direction of research on cannabis is to approach cannabis as a legitimate therapeutic agent. This would include reclassification, as well as more stringent and uniform supervision of its use and distribution in a safe, ethically, and scientifically justified manner [125-128]. Such policies would allow for improved research and consequently a better understanding of the safety and efficacy of cannabis.

In addition to rescheduling cannabis, further thought may be given to policy design. As state-based legalization becomes more common policymakers should consider how their policies affect production, price, and use. There is some evidence that legalization deflates production costs $[129,130]$, thereby potentially decreasing the market price. However, it has also been suggested that decreased cost may lead to increased use, particularly among adolescents [129]. As a result, policy makers ought to consider mechanisms to control cost. Taxes may be a useful tool to influence price and potentially adolescent use [130, 131]. Furthermore, revenue from those taxes can be utilized to promote prevention programs. Another mechanism to alter use includes limiting media promotion. Currently, only 6 jurisdictions have implemented policies restricting media advertising [123], so there is limited evidence on efficacy, but evidence from similar policies in alcohol and tobacco prevention is promising.

\section{Conclusion}

In conclusion, despite the general uncertainty on the safety and efficacy of medical and recreational cannabis use there are some general themes that remain consistent. There are clear acute cardiovascular, respiratory, cognitive, psychological, and public health effects of cannabis use. Additionally, persistent cardiovascular and respiratory consequences are fairly well documented in chronic users. The evidence of other long-term impacts of cannabis are mixed, and likely influenced by age of first use, duration of use, frequency of use, potency, and co-morbid conditions. Finally, there is evidence suggesting a therapeutic impact of cannabis on reducing spasticity associated with MS, chronic neuropathic pain, and nausea and vomiting in individuals undergoing chemotherapy. However, studies of patients with MS who used cannabis raise a cautionary note regarding further cognitive diminishment, which may affect clinical outcomes. Therapeutic potential in the treatment of other diseases is unclear and requires more research. Collectively, these findings support the continued therapeutic use of cannabis when conventional treatments are ineffective. However, when recommending medical cannabis, physicians and patients would benefit from discussions of the risks, benefits, and uncertainties associated with cannabis use. Furthermore, medical cannabis should be avoided in vulnerable populations, including individuals under the age of 25 years, individuals with current or past substance use disorders, individuals with a personal or family history of mental illness, those that have compromised cardiovascular, respiratory, or immune systems, and those who are pregnant. Finally, efforts to reclassify cannabis should continue and policy makers must consider impacts on production, price, and use when crafting legislation.

Required Author Forms Disclosure forms provided by the authors are available with the online version of this article.

Open Access This article is distributed under the terms of the Creative Commons Attribution 4.0 International License (http:// creativecommons.org/licenses/by/4.0/), which permits unrestricted use, distribution, and reproduction in any medium, provided you give appropriate credit to the original author(s) and the source, provide a link to the Creative Commons license, and indicate if changes were made.

\section{References}

1. UNODC. World Drug Report 2013. United Nations Publication Vienna, 2013.

2. Substance Abuse and Mental Health Services Administration (SAMHSA). Results from the 2013 National Survey on Drug Use and Health: Summary of national findings. Substance Abuse and Mental Health Servicels Administration, Rockville, MD, 2014.

3. Elsohly MA, Slade D. Chemical constituents of marijuana: the complex mixture of natural cannabinoids. Life Sci 2005;78: 539-548.

4. Borgelt LM, Franson KL, Nussbaum AM, Wang GS. The pharmacologic and clinical effects of medical cannabis. Pharmacother 2013;33:195-209. 
5. McPartland JM, Duncan M, Di Marzo V, Pertwee RG. Are cannabidiol and Delta(9) -tetrahydrocannabivarin negative modulators of the endocannabinoid system? A systematic review. Br J Pharmacol 2015;172:737-753.

6. Benbadis SR, Sanchez-Ramos J, Bozorg A, et al. Medical marijuana in neurology. Exp Rev Neurother 2014;14:1453-1465.

7. Mackie K. Signaling via CNS cannabinoid receptors. Mol Cell Endocrinol 2008;286:S60-S65.

8. Pertwee R. The diverse CB1 and CB2 receptor pharmacology of three plant cannabinoids: $\Delta$ 9-tetrahydrocannabinol, cannabidiol and $\Delta$ 9-tetrahydrocannabivarin. $\mathrm{Br} \mathrm{J}$ Pharmacol 2008;153: 199-215.

9. Pertwee RG. Cannabinoid pharmacology: the first 66 years. Br J Pharmacol 2006;147(Suppl. 1):S163-S171.

10. Piomelli D. The molecular logic of endocannabinoid signalling. Nat Rev Neurosci 2003;4:873-884.

11. Pertwee R. Receptors and channels targeted by synthetic cannabinoid receptor agonists and antagonists. Curr Med Chem 2010;17: 1360.

12. Suarez-Pinilla P, Lopez-Gil J, Crespo-Facorro B. Immune system: a possible nexus between cannabinoids and psychosis. Brain Behav Immun 2014;40:269-282.

13. Machado Bergamaschi M, Helena Costa Queiroz R, Waldo Zuardi A, Crippa AS. Safety and side effects of cannabidiol, a Cannabis sativa constituent. Curr Drug Saf 2011;6:237-249.

14. Pope C, Mechoulam R, Parsons L. Endocannabinoid signaling in neurotoxicity and neuroprotection. Neurotoxicology 2010;31: 562-571.

15. Schatman ME. Medical Marijuana: the state of the science. Medscape Neurology [Internet] 2015. [cited 2015 April 20]. Available from: http://www.medscape.com/viewarticle/839155

16. Adams IB, Martin BR. Cannabis: pharmacology and toxicology in animals and humans. Addiction 1996;91:1585-11614.

17. Cascini F, Aiello C, Di Tanna G. Increasing delta-9tetrahydrocannabinol $(\Delta-9-\mathrm{THC})$ content in herbal cannabis over time: systematic review and meta-analysis. Curr Drug Abuse Rev 2012;5:32-40.

18. Fitzgerald KT, Bronstein AC, Newquist KL. Marijuana poisoning. Top Companion Anim Med 2013;28:8-12.

19. McLaren J, Swift W, Dillon P, Allsop S. Cannabis potency and contamination: a review of the literature. Addiction 2008;103: 1100-1109.

20. Repp K, Raich A. Marijuana and health: a comprehensive review of 20 years of research. Washington County Oregon: Department of Health and Human Services; 2014.

21. Robson P. Human studies of cannabinoids and medicinal cannabis. Handb Exp Pharmacol 2005;(168):719-786.

22. Scallet AC. Neurotoxicology of cannabis and THC: a review of chronic exposure studies in animals. Pharmacol Biochem Behav 1991;40:671-676.

23. Wall ME, Sadler BM, Brine D, Taylor H, Perez-Reyes M. Metabolism, disposition, and kinetics of delta-9-tetrahydrocannabinol in men and women. Clin Pharmacol Ther 1983;34: 352-363.

24. Zuurman L, Ippel AE, Moin E, Van Gerven J. Biomarkers for the effects of cannabis and THC in healthy volunteers. Br J Clin Pharmacol 2009;67:5-21.

25. Zuurman L, Passier P, de Kam M, Kleijn H, Cohen A, van Gerven $\mathrm{J}$. Pharmacodynamic and pharmacokinetic effects of the intravenously administered CB1 receptor agonist Org 28611 in healthy male volunteers. J Psychopharmacol 2009;23:633-644.

26. Grotenhermen F. The toxicology of cannabis and cannabis prohibition. Chem Biodivers 2007;4:1744-1769.

27. Hall W. The adverse health effects of cannabis use: what are they, and what are their implications for policy? Int J Drug Policy 2009;20:458-466.
28. Hall W, Degenhardt L. Adverse health effects of non-medical cannabis use. Lancet 2009;374:1383-1391.

29. Reece AS. Chronic toxicology of cannabis. J Clin Toxicol 2009; $47: 517-524$

30. Thomas G, Kloner RA, Rezkalla S. Adverse cardiovascular, cerebrovascular, and peripheral vascular effects of marijuana inhalation: what cardiologists need to know. Am J Cardiol 2014;113: 187-190.

31. Kahan M, Srivastava A, Spithoff S, Bromley L. Prescribing smoked cannabis for chronic noncancer pain: preliminary recommendations. Can Fam Physician 2014;60:1083-1090.

32. Parakh P. Adverse health effects of non-medical cannabis use. Lancet 2010;375:196-197.

33. Tormey W. Adverse health effects of non-medical cannabis use. Lancet 2010;375:196.

34. Volkow ND, Baler RD, Compton WM, Weiss SR. Adverse health effects of marijuana use. N Engl J Med 2014;370:2219-2227.

35. Kalant $\mathrm{H}$. Adverse effects of cannabis on health: an update of the literature since 1996. Prog Neuropsychopharmacol Biol Psychiatry 2004;28:849-863.

36. Hashibe M, Straif K, Tashkin DP, Morgenstern H, Greenland S, Zhang ZF. Epidemiologic review of marijuana use and cancer risk. Alcohol 2005;35:265-275.

37. Maertens RM, White PA, Williams A, Yauk CL. A global toxicogenomic analysis investigating the mechanistic differences between tobacco and marijuana smoke condensates in vitro. Toxicology 2013;308:60-73.

38. Gates PJ, Albertella L, Copeland J. The effects of cannabinoid administration on sleep: a systematic review of human studies. Sleep Med Rev 2014;18:477-487.

39. Tramèr MR, Carroll D, Campbell FA, Reynolds DJM, Moore RA, McQuay HJ. Cannabinoids for control of chemotherapy induced nausea and vomiting: quantitative systematic review. BMJ 2001;323:16.

40. Yamamoto I, Watanabe K, Matsunaga T, Kimura T, Funahashi T, Yoshimura H. Pharmacology and toxicology of major constituents of marijuana - on the metabolic activation of cannabinoids and its mechanism. Toxin Rev 2003;22:577-589.

41. Zhornitsky S, Potvin S. Cannabidiol in humans - the quest for therapeutic targets. Pharmaceuticals 2012;5:529-552.

42. Lynch ME, Campbell F. Cannabinoids for treatment of chronic non-cancer pain; a systematic review of randomized trials. $\mathrm{Br} \mathrm{J}$ Clin Pharmacol 2011;72:735-744.

43. Roitman P, Mechoulam R, Cooper-Kazaz R, Shalev A. Preliminary, open-label, pilot study of add-on oral Delta9tetrahydrocannabinol in chronic post-traumatic stress disorder. Clin Drug Investig 2014;34:587-591.

44. Kobayashi H, Suzuki T, Kamata R, et al. Recent progress in the neurotoxicology of natural drugs associated with dependence or addiction, their endogenous agonists and receptors. J Toxicol Sci 1999;24:1-16.

45. Crane NA, Schuster RM, Fusar-Poli P, Gonzalez R. Effects of cannabis on neurocognitive functioning: recent advances, neurodevelopmental influences, and sex differences. Neuropsychol Rev 2013;23:117-137.

46. Meier MH, Caspi A, Ambler A, et al. Persistent cannabis users show neuropsychological decline from childhood to midlife. Proc Natl Acad Sci 2012;109:E2657-E2664.

47. Schoeler T, Bhattacharyya S. The effect of cannabis use on memory function: an update. Subst Abuse Rehabil 2013;4:11-27.

48. Ehrler M, McGlade EC, Yurgelun-Todd D. Subjective and cognitive effects of cannabinoids in marijuana smokers. In: Campolongo P, Fattore L, editors. Cannabinoid modulation of emotion, memory, and motivation. New York: Springer; 2015. p. 159-181. 
49. Wrege J, Schmidt A, Walter A, et al. Effects of cannabis on impulsivity: a systematic review of neuroimaging findings. Curr Pharm Des 2014;20:2126.

50. Crean RD, Crane NA, Mason BJ. An evidence based review of acute and long-term effects of cannabis use on executive cognitive functions. J Addict Med 2011;5:1.

51. Gonzalez R, Carey C, Grant I. Nonacute (residual) neuropsychological effects of cannabis use: a qualitative analysis and systematic review. J Clin Pharmacol 2002;42(Suppl.1):48S-57S.

52. Solowij N, Pesa N. Cognitive abnormalities and cannabis use. Rev Bras Psiquiatr 2010;32:531-540.

53. Pope HG, Gruber AJ, Hudson JI, Huestis MA, Yurgelun-Todd D. Cognitive Measures in long-term cannabis users. J Clin Pharmacol 2002;42(Suppl. 1):41S-47S.

54. Pope Jr HG, Gruber AJ, Yurgelun-Todd D. Residual neuropsychologic effects of cannabis. Curr Psychiatry Rep 2001;3:507-512.

55. Grant I, Gonzalez R, Carey CL, Natarajan L, Wolfson T. Nonacute (residual) neurocognitive effects of cannabis use: a metaanalytic study. J Int Neuropsychol Soc 2003;9:679-689.

56. Schweinsburg AD, Brown SA, Tapert SF. The influence of marijuana use on neurocognitive functioning in adolescents. Curr Drug Abuse Rev 2008;1:99.

57. James A, James C, Thwaites T. The brain effects of cannabis in healthy adolescents and in adolescents with schizophrenia: a systematic review. Psychiatry Res 2013;214:181-189.

58. Pope HG, Gruber AJ, Hudson JI, Cohane G, Huestis MA, Yurgelun-Todd D. Early-onset cannabis use and cognitive deficits: what is the nature of the association? Drug Alcohol Depend 2003;69:303-310.

59. Pope HG, Yurgelun-Todd D. The residual cognitive effects of heavy marijuana use in college students. JAMA 1996;275: 521-527.

60. Batalla A, Bhattacharyya S, Yucel M, et al. Structural and functional imaging studies in chronic cannabis users: a systematic review of adolescent and adult findings. PloS One 2013;8:e55821.

61. Lorenzetti V, Lubman DI, Whittle S, Solowij N, Yucel M. Structural MRI findings in long-term cannabis users: what do we know? Substance Use Misuse 2010;45:1787-1808.

62. Martin-Santos R, Fagundo AB, Crippa JA, et al. Neuroimaging in cannabis use: a systematic review of the literature. Psychol Med 2010;40:383-398.

63. Rapp C, Bugra H, Riecher-Rössler A, Tamagni C, Borgwardt S. Effects of cannabis use on human brain structure in psychosis: a systematic review combining in vivo structural neuroimaging and post mortem studies. Curr Pharm Des 2012;18:5070.

64. Lopez-Larson MP, Bogorodzki P, Rogowska J, et al. Altered prefrontal and insular cortical thickness in adolescent marijuana users. Behav Brain Res 2011;220:164-172.

65. McCormick MA, Shekhar A. Review of marijuana use in the adolescent population and implications of its legalization in the United States. J Drug Metab Toxicol 2014;5:2.

66. Jacobus J, Squeglia LM, Meruelo AD, et al. Cortical thickness in adolescent marijuana and alcohol users: a three-year prospective study from adolescence to young adulthood. Dev Cog Neurosci 2015 Apr 27 [Epub ahead of print].

67. Wetherill RR, Jagannathan K, Hager N, Childress AR, Rao H, Franklin TR. Cannabis, cigarettes, and their co-occurring use: disentangling differences in gray matter volume. Int $\mathrm{J}$ Neuropsychopharmacol 2015:pyv061.

68. Gruber SA, Yurgelun-Todd DA. Neuroimaging of marijuana smokers during inhibitory processing: a pilot investigation. Cog Brain Res 2005;23:107-118.

69. Churchwell JC, Yurgelun-Todd DA. Neuroimaging, adolescence, and risky behavior. In: MT B, DH F, R M (eds) Inhibitory control and drug abuse prevention. Springer, ??, 2011, pp. 101-122.
70. Kanayama G, Rogowska J, Pope HG, Gruber SA, Yurgelun-Todd DA. Spatial working memory in heavy cannabis users: a functional magnetic resonance imaging study. Psychopharmacol 2004; 176:239-247.

71. Chang L, Cloak C, Yakupov R, Ernst T. Combined and independent effects of chronic marijuana use and HIV on brain metabolites. J Neuroimmune Pharmacol 2006;1:65-76.

72. Hermann D, Sartorius A, Welzel H, et al. Dorsolateral prefrontal cortex $\mathrm{N}$-acetylaspartate/total creatine (NAA/tCr) loss in male recreational cannabis users. Biol Psychol 2007;61:1281-1289.

73. Prescot AP, Renshaw PF, Yurgelun-Todd DA. $\gamma$-Amino butyric acid and glutamate abnormalities in adolescent chronic marijuana smokers. Drug Alcohol Depend 2013;129:232-239.

74. Crippa JAS, Derenusson GN, Ferrari TB, et al. Neural basis of anxiolytic effects of cannabidiol (CBD) in generalized social anxiety disorder: a preliminary report. J Psychopharmacol 2011;25: 121-130.

75. Gibbs M, Winsper C, Marwaha S, Gilbert E, Broome M, Singh SP. Cannabis use and mania symptoms: a systematic review and meta-analysis. J Affect Disord 2015;171:39-47.

76. Lev-Ran S, Roerecke M, Le Foll B, George TP, McKenzie K, Rehm J. The association between cannabis use and depression: a systematic review and meta-analysis of longitudinal studies. Psychol Med 2014;44:797-810.

77. Crippa JA, Zuardi AW, Martin-Santos R, et al. Cannabis and anxiety: a critical review of the evidence. Hum Psychopharmacol 2009;24:515-523.

78. Nussbaum AM, Thurstone C, McGarry L, Walker B, Sabel AL. Use and diversion of medical marijuana among adults admitted to inpatient psychiatry. Am J Drug Alcohol Abuse 2015;41:166-172.

79. Ferretjans R, Moreira FA, Teixeira AL, Salgado JV. The endocannabinoid system and its role in schizophrenia: a systematic review of the literature. Rev Bras Psiquiatr 2012;34:163-193.

80. Semple DM, McIntosh AM, Lawrie SM. Cannabis as a risk factor for psychosis: systematic review. J Psychopharmacol 2005;19: 187-194.

81. Moore THM, Zammit S, Lingford-Hughes A, et al. Cannabis use and risk of psychotic or affective mental health outcomes: a systematic review. Lancet 2007;370:319-328.

82. Szoke A, Galliot AM, Richard JR, et al. Association between cannabis use and schizotypal dimensions - a meta-analysis of cross-sectional studies. Psychiatry Res 2014;219:58-66.

83. Malchow B, Hasan A, Fusar-Poli P, Schmitt A, Falkai P, Wobrock T. Cannabis abuse and brain morphology in schizophrenia: a review of the available evidence. Eur Arch Psychiatry Clin 2013;263:3-13.

84. J van der Meer F, Velthorst E, J Meijer C, WJ Machielsen M, de Haan L. Cannabis use in patients at clinical high risk of psychosis: impact on prodromal symptoms and transition to psychosis. Curr Pharm Des 2012;18:5036-5044.

85. Iseger TA, Bossong MG. A systematic review of the antipsychotic properties of cannabidiol in humans. Schizophr Res 2015;162: 153-161.

86. Roser P, S Haussleiter I. Antipsychotic-like effects of cannabidiol and rimonabant: systematic review of animal and human studies. Curr Pharm Des 2012;18:5141-5155.

87. Calabria B, Degenhardt L, Hall W, Lynskey M. Does cannabis use increase the risk of death? Systematic review of epidemiological evidence on adverse effects of cannabis use. Drug Alcohol Rev 2010;29:318-330.

88. Johnston LD, Miech RA, O'Malley PM, Bachman JG, Schulenberg JE. Use of alcohol, cigarettes, and number of illicit drugs declines among U.S. teens. Ann Arbor, MI, 2014/ Retrieved 20 Apr. 2015. Report No.

89. National Intstitute of Drug Abuse (NIDA). Research Report Series: Marijuana. 2015. 
90. Goldschmidt L, Day NL, Richardson GA. Effects of prenatal marijuana exposure on child behavior problems at age 10 . Neurotoxicol Teratol 2000;22:325-336.

91. Richardson GA, Ryan C, Willford J, Day NL, Goldschmidt L. Prenatal alcohol and marijuana exposure: effects on neuropsychological outcomes at 10 years. Neurotoxicol Teratol 2002;24:309-320.

92. de Moraes Barros MC, Guinsburg R, Mitsuhiro S, Chalem E, Laranjeira RR. Neurobehavioral profile of healthy full-term newborn infants of adolescent mothers. Early Hum Dev 2008;84:281287

93. Fried PA, Makin J. Neonatal behavioural correlates of prenatal exposure to marihuana, cigarettes and alcohol in a low risk population. Neurotoxicol Teratol 1987;9:1-7.

94. Mincis M, Pfeferman A, Guimarães R, Ramos O, Zukerman E, Karniol I, et al. [Chronic administration of cannabidiol in man. Pilot study]. AMB Rev Assoc Med Bras 1973;19:185-190 (in Portuguese).

95. Koppel BS, Brust JC, Fife T, et al. Systematic review: efficacy and safety of medical marijuana in selected neurologic disorders: report of the Guideline Development Subcommittee of the American Academy of Neurology. Neurology 2014;82:15561563.

96. Lakhan SE, Rowland M. Whole plant cannabis extracts in the treatment of spasticity in multiple sclerosis: a systematic review. BMC Neurol 2009;9:59.

97. O'Reilly K. AMA meeting: delegates support review of marijuana's schedule I status. American Medical New [Internet] 2009. [cited 2015 Apr 20]. Available from: http://www. amednews.com/article/20091123/profession/311239968/7/

98. Wade DT, Makela P, House H, Bateman C, Robson P. Long-term use of a cannabis-based medicine in the treatment of spasticity and other symptoms in multiple sclerosis. Multiple Sclerosis 2006;12: 639-645.

99. Pavisian B, MacIntosh BJ, Szilagyi G, Staines RW, O'Connor P, Feinstein A. Effects of cannabis on cognition in patients with MS A psychometric and MRI study. Neurology 2014;82:1879-1887.

100. Honarmand K, Tierney MC, O'Connor P, Feinstein A. Effects of cannabis on cognitive function in patients with multiple sclerosis. Neurololgy 2011;76:1153-1160.

101. Ghaffar O, Feinstein A. Multiple sclerosis and cannabis: a cognitive and psychiatric study. Neurology 2008;71:164-169.

102. Gloss D, Vickrey B. Cannabinoids for epilepsy. Cochrane Database Syst Rev 2012;6:CD009270.

103. Krishnan S, Cairns R, Howard R. Cannabinoids for the treatment of dementia. Cochrane Database Syst Rev 2009;(2):CD007204.

104. Solas M, Francis PT, Franco R, Ramirez MJ. CB 2 receptor and amyloid pathology in frontal cortex of Alzheimer's disease patients. Neurobiol Aging 2013;34:805-808

105. Esposito G, De Filippis D, Carnuccio R, Izzo AA, Iuvone T. The marijuana component cannabidiol inhibits $\beta$-amyloid-induced tau protein hyperphosphorylation through $\mathrm{Wnt} / \beta$-catenin pathway rescue in PC12 cells. J Mol Med 2006;84:253-258

106. Eubanks LM, Rogers CJ, Beuscher AE, IV, et al. A molecular link between the active component of marijuana and Alzheimer's disease pathology. Mol Pharm 2006;3:773-777.

107. Fox SH, Henry B, Hill M, Crossman A, Brotchie J. Stimulation of cannabinoid receptors reduces levodopa-induced dyskinesia in the MPTP-lesioned nonhuman primate model of Parkinson's disease. Mov Disord 2002;17:1180-1187.

108. Sagredo O, Ruth Pazos M, Valdeolivas S, Fernández-Ruiz J. Cannabinoids: novel medicines for the treatment of Huntington's disease. Recent Pat CNS Drug Discov 2012;7:41-48

109. McLoughlin BC, Pushpa-Rajah JA, Gillies D, et al. Cannabis and schizophrenia. Cochrane Database Syst Rev 2014;10:CD004837.
110. Zuardi AW, Hallak JE, Dursun SM, et al. Cannabidiol monotherapy for treatment-resistant schizophrenia. J Psychopharmacol 2006;20:683-686.

111. Boychuk DG, Goddard G, Mauro G, Orellana MF. The effectiveness of cannabinoids in the management of chronic nonmalignant neuropathic pain: a systematic review. J Oral Facial Pain Headache 2015;29:7-14.

112. Eisenberg E, Ogintz M, Almog S. The pharmacokinetics, efficacy, safety, and ease of use of a novel portable metered-dose cannabis inhaler in patients with chronic neuropathic pain: a phase 1a study. J Pain Palliat Care Pharmacother 2014;28:216-225.

113. Martin-Sanchez E, Furukawa TA, Taylor J, Martin JL. Systematic review and meta-analysis of cannabis treatment for chronic pain. Pain Med 2009;10:1353-1368.

114. Richards BL, Whittle SL, Buchbinder R. Neuromodulators for pain management in rheumatoid arthritis. Cochrane Database Syst Rev 2012;1:CD008921.

115. Canadian Agency for Drugs and Technologies in Health (CADTH). CADTH rapid response reports. CADTH, Ottawa, 2014.

116. Machado Rocha FC, Stefano SC, De Cassia Haiek R, Rosa Oliveira LM, Da Silveira DX. Therapeutic use of Cannabis sativa on chemotherapy-induced nausea and vomiting among cancer patients: systematic review and meta-analysis. Eur J Cancer Care 2008:17:431-443.

117. Wang T, Collet JP, Shapiro S, Ware MA. Adverse effects of medical cannabinoids: a systematic review. CMAJ 2008;178: 1669-1678.

118. Mack A, Joy J. Marijuana as medicine?: the science beyond the controversy: National Academies Press, 2000.

119. Kassirer JP. Federal foolishness and marijuana. N Engl J Med 1997;336:366.

120. Lopez-Pelayo H, Batalla A, Balcells MM, Colom J, Gual A. Assessment of cannabis use disorders: a systematic review of screening and diagnostic instruments. Psychol Med 2015;45: 1121-1133.

121. Substance Abuse and Mental Health Services Administration (SAMHSA). Results from the 2012 National Survey on Drug Use and Health: summary of national findings. Substance Abuse and Mental Health Services Administration, Rockville, MD, 2013.

122. Okaneku J, Vearrier D, McKeever RG, LaSala GS, Greenberg MI. Change in perceived risk associated with marijuana use in the United States from 2002 to 2012. Clin Toxicol 2015;53:151-155.

123. Research PHL. Laws, maps \& data: law atlas. Robert Wood Johnson Foundation.

124. Pacula RL, Hunt P, Boustead A. Words can be deceiving: a review of variation among legally effective medical marijuana laws in the United States. J Drug Policy Anal 2014;7:1-19.

125. Blumenson E, Nilsen E. No rational basis: the pragmatic case for marijuana law reform. Va J Soc Pol'y \& L. 2009;17:43.

126. Bostwick JM. Blurred boundaries: the therapeutics and politics of medical marijuana. Mayo Clin Proc 2012;87:172-186.

127. Bostwick JM. The use of cannabis for management of chronic pain. Gen Hosp Psychiatry 2014;36:2-3.

128. Cohen PJ. Medical marijuana 2010: it's time to fix the regulatory vacuum. J Law Med Ethics 2010;38:654-666.

129. Caulkins JP, Hawken A, Kilmer B, Kleiman MA. Marijuana Legalization: what everyone needs to know. Oxford, Oxford University Press, 2012.

130. Kilmer B. Policy designs for cannabis legalization: starting with the eight Ps. Am J Drug Alcohol Ab 2014;40:259-261.

131. Caulkins JP, Hawken A, Kilmer B, Kleiman MA. High tax states: options for gleaning revenue from legal cannabis. Or L Rev 2012;91:1041. 